\title{
Lung development in laminin $\gamma 2$ deficiency: abnormal tracheal hemidesmosomes with normal branching morphogenesis and epithelial differentiation
}

\author{
Nguyet M Nguyen ${ }^{1}$, Leena Pulkkinen ${ }^{3}$, Jessica A Schlueter ${ }^{1}$, \\ Guerrino Meneguzzi ${ }^{4}$, Jouni Uitto ${ }^{5,6}$ and Robert M Senior*1,2
}

Address: ${ }^{1}$ Department of Internal Medicine, Washington University School of Medicine, St. Louis, Missouri, USA, ${ }^{2}$ Department of Cell Biology \& Physiology, Washington University School of Medicine, St. Louis, Missouri, USA, ${ }^{3}$ Department of Clinical Nutrition, University of Kuopio, Kuopio, Finland, ${ }^{4}$ INSERM U634, School of Medicine, University of Nice-Sophia Antipolis, Nice, France, ${ }^{5}$ Department of Dermatology and Cutaneous Biology, Jefferson Medical College, Thomas Jefferson University, Philadelphia, Pennsylvania, USA and ${ }^{6}$ Department of Biochemistry and Molecular Biology, Jefferson Medical College, Thomas Jefferson University, Philadelphia, Pennsylvania, USA

Email: Nguyet M Nguyen - nnguyen@im.wustl.edu; Leena Pulkkinen - leena.pulkkinen@uku.fi; Jessica A Schlueter - jschluet@im.wustl.edu; Guerrino Meneguzzi - guerrino.meneguzzi@unice.fr; Jouni Uitto - jouni.uitto@jefferson.edu; Robert M Senior* - rsenior@im.wustl.edu

* Corresponding author

Published: 16 February 2006

Respiratory Research 2006, 7:28 doi:10.1 186/1465-992I-7-28
Received: 29 November 2005

Accepted: 16 February 2006

This article is available from: http://respiratory-research.com/content/7/I/28

(c) 2006 Nguyen et al; licensee BioMed Central Ltd.

This is an Open Access article distributed under the terms of the Creative Commons Attribution License (http://creativecommons.org/licenses/by/2.0), which permits unrestricted use, distribution, and reproduction in any medium, provided the original work is properly cited.

\begin{abstract}
Background: Laminin $\gamma 2$ (Lamc2), one of the polypeptides in laminin-332 (laminin-5), is prominent in the basement membrane of alveolar walls and airways of developing and adult lung. Laminins are important for lung morphogenesis and based on its localization, a function for laminin $\gamma 2$ in lung development has been hypothesized. Targeted deletion of the laminin $\gamma 2$ gene in mice results in skin blistering and neonatal death at 3-5 days after birth due to failure to thrive.
\end{abstract}

Methods: Examination of lung development in Lamc2-I- mice through I-2 days postnatal was accomplished by morphometric analysis, lung bud culture, electron microscopy, immunohistochemical and immunofluorescence staining.

Results: Compared to littermate controls, Lamc2-/- lungs were similar in morphology during embryonic life. At post-natal day I-2, distal saccules were mildly dilated by chord length measurements. Epithelial differentiation as evaluated by immunohistochemical staining for markers of ciliated cells, Clara cells, alveolar type I cells and alveolar type II cells did not reveal a difference between Lamc2-I- and littermate control lungs. Likewise, vascular development, smooth muscle cell differentiation, and elastic fiber formation looked similar, as did airway basement membrane ultrastructure. Branching morphogenesis by lung bud culture was similar in Lamc2-/- and littermate control lungs. Since laminin-332 is important for hemidesmosome formation, we examined the structure of tracheal hemidesmosomes by transmission electron microscopy. Compared to littermate controls, Lamc2-/- tracheal hemidesmosomes were less organized and lacked the increased electron density associated with the basement membrane abutting the hemidesmosome.

Conclusion: These findings indicate that laminin $\gamma 2$ and laminin-332, despite their prominence in the lung, have a minimal role in lung development through the saccular stage. 


\section{Background}

Lung morphogenesis requires coordinated input from a multitude of diverse molecules ranging from transcription factors to growth factors to cytokines and extracellular matrix. Basement membranes are specialized extracellular matrices that have vital roles in cell adhesion, migration, differentiation, as well as in tissue organization and development [1]. Laminins, type IV collagen, entactin/nidogen, and sulfated proteoglycans are the main components of basement membranes. Laminins are heterotrimers composed of one $\alpha$, one $\beta$, and one $\gamma$ chain. To date, $5 \alpha$ chains, $4 \beta$ chains, and $3 \gamma$ chains are present in humans and mice and these laminin chains self-assemble to form at least 15 laminins [2].

The lung is rich in laminin chains and all but the laminin $\gamma 3$ chain (which is not present in lung basement membrane [3]) are detected in the lung at some point during development and in adult lungs. The laminin $\alpha 1-\alpha 5, \beta 1-$ $\beta 3$, and $\gamma 1-\gamma 2$ chains are present in embryonic lung; laminin $\alpha 2-\alpha 5, \beta 1-\beta 3$, and $\gamma 1-\gamma 2$ chains are present in the adult lung [4-7]. Studies of lung development from our laboratory and others have shown that laminin and its interactions are crucial for lung morphogenesis. Epithelial-derived laminin chains are important for lung development since addition of either laminin-111 (formerly laminin-1) antibodies or proteolytic fragments to lung bud cultures perturbs branching morphogenesis [8]. Interference with entactin/nidogen binding to laminin through ablation of the nidogen-binding site on laminin $\gamma 1$ in vivo affects sacculation [9]. Mesenchymal cellderived laminin $\alpha 2$ is required for bronchial smooth muscle cell differentiation in vitro [10]. Targeted deletion of laminin $\alpha 5$ in the mouse results in abnormal lobar septation, absence of visceral pleura basement membrane, and ectopic deposition of laminin $\alpha 4$ in lungs through embryonic day 16.5 at which time these mice die [11]. Ablation of laminin $\alpha 5$ expression by lung epithelial cells alone via the SP-C promoter and the Cre/LoxP system enabled examination of lungs up to post-natal day 1 . The lungs had grossly enlarged distal airspaces and markedly impaired distal epithelial cell differentiation [11]. Thus, multiple in vitro and in vivo studies have shown that laminins are important for lung development at different stages.

Laminin $\gamma 2$ which is unique to laminin-332 (formerly laminin-5), localizes to airway epithelial basement membranes during lung development leading to speculation that it is required for lung development [12-14]. Laminin $\gamma 2$ null (Lamc2-/-) mice exhibit blistering and erosions of the skin and die a few days after birth presumably due to malnutrition as a result of blistering and erosions in the oral cavity [15], but the lungs have not been described. In this investigation, we report findings regarding lung development in Lamc2-/- mice.

\section{Methods \\ Production, breeding and genotyping of mice}

Production of Lamc2-/- mice has been described previously in detail [15]. Lamc2-/- mice were maintained on a mixed 129/C57BL/6J background. Timed matings of mice were established to produce Lamc2-/- and littermate control offspring at various ages. Noon on the day of detection of a vaginal plug was designated as E0.5. Genomic DNA was obtained from tails using the Qiagen DNA kit (Qiagen, Carlsbad CA). Genotyping was completed by PCR with laminin $\gamma 2$ specific primers, wild type forward 5'-CCG CTT GCT GAC TTG TAT CC-3', Lamc2-/- forward 5'-AGC TAA TAC GGG TTC AGC C-3', reverse 5'-TGT AAC CAG AAG CAC ATT CC-3'. The Washington University Animal Studies Committee approved all experiments.

\section{Antibodies}

Rat monoclonal antibody to murine laminin $\alpha 1$ was from Dale Abrahamson (University of Kansas Medical Center). Rabbit polyclonal antibodies to laminin $\alpha 3 \mathrm{~A}$ and $\alpha 3 \mathrm{~B}$ were from Takako Sasaki (Max Planck Institute of Biochemistry, Martinsreid, Germany) [16]. Rabbit polyclonal antibodies to entactin/nidogen [17], laminin $\alpha 5$ [4], laminin $\alpha 4$ [18], and laminin $\gamma 2$ [19] were produced as described. Antibody against integrin $\alpha 3$ was from C. Michael DiPersio (Albany Medical College). Antibody against BP180 (also known as bullous pemphigoid BP antigen 2 and type XVII collagen, a major component of the epidermal anchoring complex) was from Zhi Liu (University of North Carolina, Chapel Hill, NC). Antibodies purchased from commercial suppliers were anti laminin $\alpha 2$ (4H8-2, Alexis Biochemicals, San Diego, CA), PECAM, integrin $\beta 4$ (Pharmingen, San Diego, CA), laminin $\gamma 1$, laminin $\beta 1$, integrin $\alpha 6$, aquaporin-5, CC26, prosurfactant protein C (SP-C) (Chemicon, Temecula, CA), $\beta$-tubulin IV (Biogenex, San Ramon, CA), and $\alpha$-smooth muscle actin (Sigma, St. Louis, MO). FITC- and TRITCconjugated anti-rabbit and anti-rat secondary antibodies were from Jackson ImmunoResearch Laboratories (West Grove, PA). FITC-anti-mouse IgG2b secondary antibody was from ICN Biomedicals, Inc. (Costa Mesa, CA).

\section{Immunofluorescence microscopy}

Newborn pups were sacrificed by decapitation and immediately immersed in Tissue Tek OCT embedding medium (Sakura Finetek, Torrance, CA), frozen in liquid nitrogencooled 2-methylbutane, and sectioned at $6 \mu \mathrm{m}$ on a cryostat. Sections were blocked with $10 \%$ normal goat serum in $1 \% \mathrm{BSA} / \mathrm{PBS}$, then incubated with primary antibody diluted in $1 \%$ BSA/PBS. Slides were washed with PBS, and incubated with secondary antibody diluted in 1\% BSA/ PBS. Slides were again washed with PBS and mounted in 

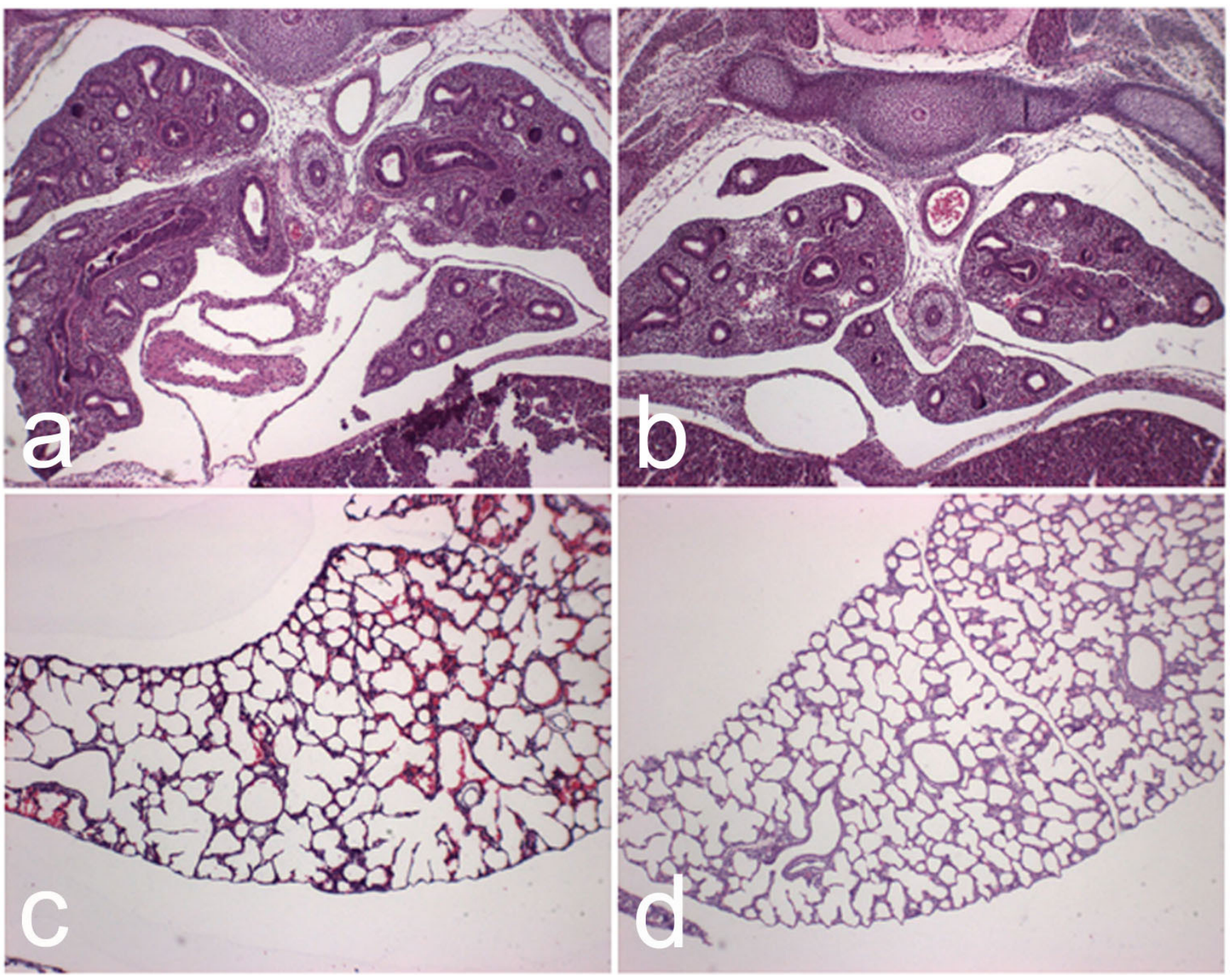

Figure I

Lung histology and morphometry. Paraffin sections $(5 \mu \mathrm{m})$ of Lamc2-/- $(\mathrm{a}, \mathrm{c})$ and littermate control (b, d) lungs at El4.5 (a, b) and PI-2 (c, d) were stained with hematoxylin and eosin. At El4.5, histology of Lamc2-/- (a) lung was indistinguishable from those of littermate control (b). At PI-2 Lamc2-/- (c) lungs had mildly enlarged saccules compared with those of littermate control (d). Original magnification $100 \times(a, b)$, and $40 \times(c, d)$.

Vectashield (Vector Laboratories, Temecula, CA). For laminin $\alpha 4$ staining, sections were fixed in $4 \%$ paraformaldehyde for 10 minutes, washed in PBS, treated with $0.1 \mathrm{M}$ glycine, $\mathrm{pH} 3.5$, for 10 minutes, washed in PBS, treated with $0.1 \%$ SDS at $55^{\circ} \mathrm{C}$ for 1 hour, washed in PBS, blocked, and stained as with other antibodies. For PECAM staining, sections were fixed in $100 \%$ ethanol prior to addition of the PECAM antibody. Antibody dilutions were 1:500 for laminins $\alpha 1-\alpha 4,1: 600$ for laminin $\alpha 5$, 1:200 for laminin $\gamma 1,1: 800$ for laminin $\gamma 2$, and 1:50 for aquaporin-5.

\section{Electron microscopy}

For transmission electron microscopy, lungs from newborn pups were fixed in 3\% glutaraldehyde in $0.1 \mathrm{M}$ sodium cacodylate buffer, postfixed with aqueous $1.25 \%$ osmium tetroxide, stained with $4 \%$ aqueous uranyl acetate, dehydrated through an ethanol series, embedded in Polybed, sectioned on a Reichert-Jung Ultra Cut, poststained in 4\% uranyl acetate and lead citrate, and viewed on a Zeiss 902 electron microscope. All reagents for electron microscopy were purchased from Electron Microscopy Sciences (Ft. Washington, PA) except Polybed (Polysciences, Warrington, PA). 

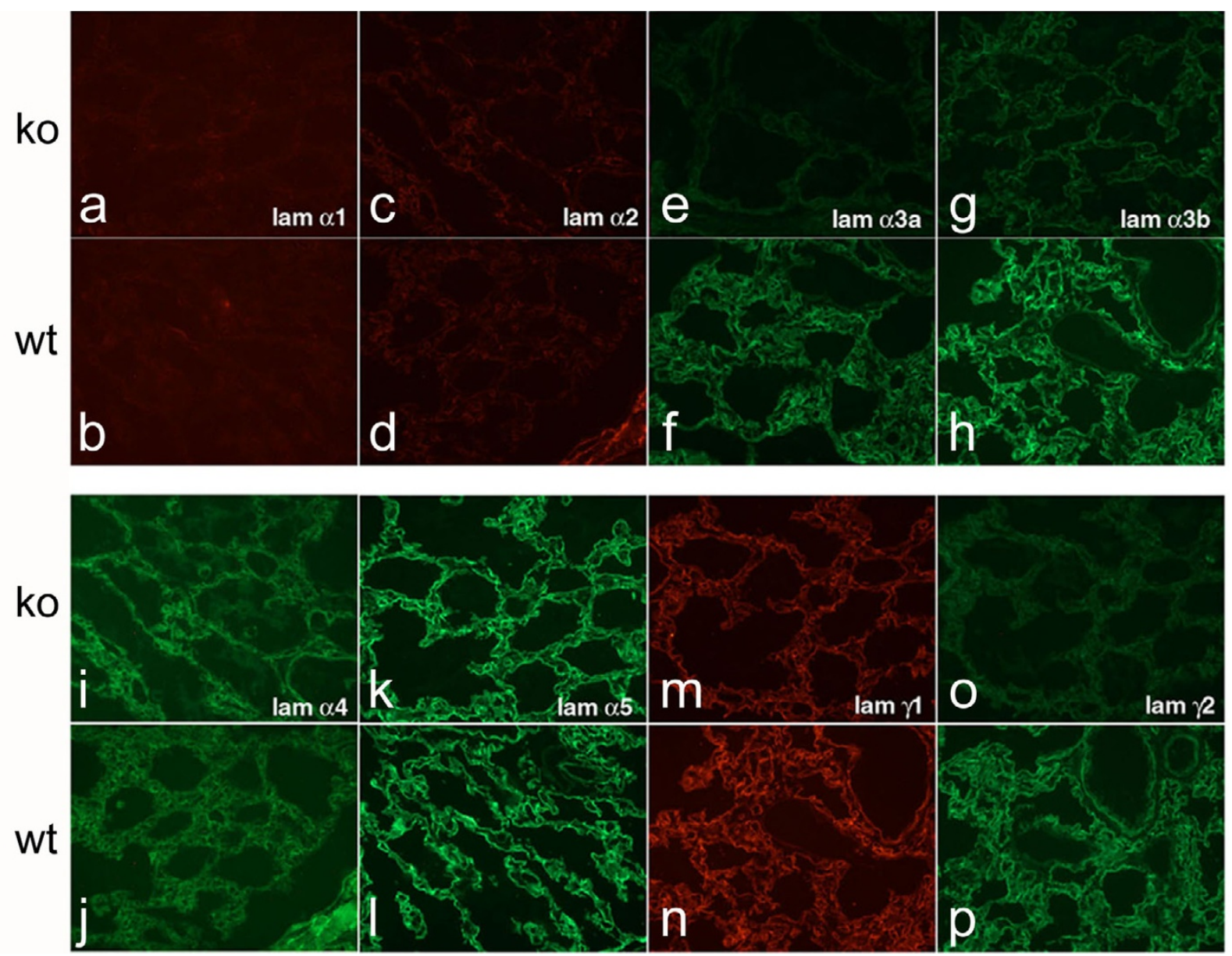

\section{Figure 2}

Deposition of laminin chains. Sections from newborn littermate control (b, d, f, h, j, l, n, p) and Lamc2-/- lungs (a, c, e, g, i, k, m, o) were stained with antibodies to laminins $\alpha I-5$ and $\gamma l-2$. The laminin $\alpha l(a, b)$ and $\alpha 2(c, d)$ chains were not detected at this stage. Laminin $\alpha 3 \mathrm{~A}(\mathrm{e}-\mathrm{f})$ and $\alpha 3 \mathrm{~B}(\mathrm{~g}-\mathrm{h})$ chains were present but diminished in the airway basement membrane of Lamc2-/- (e, $g$ ) compared to littermate control (f, h) lungs. Laminin $\alpha 4(\mathrm{i}-\mathrm{j}), \alpha 5(\mathrm{k}-\mathrm{l})$, and $\gamma \mathrm{l}(\mathrm{m}-\mathrm{n})$ chains were present and similar in Lamc2-/$(\mathrm{i}, \mathrm{k}, \mathrm{m})$ and littermate control (j, I, n) lungs. Laminin $\gamma 2$ is absent in Lamc2-/- (o) compared with littermate control (p) lungs. Original magnification $200 \times$.

\section{Histology and immunohistochemistry}

Thoraces of newborn pups were isolated by decapitation and transection at the level of the liver. Thoraces were fixed in 4\% paraformaldehyde in PBS, dehydrated in graded ethanols, embedded in paraffin, sectioned, and stained with hematoxylin and eosin for light microscopy.

For staining with $\beta$-tubulin, CC26, and SP-C antibodies 5 $\mu \mathrm{m}$ paraffin sections were immunostained using Vectastain Elite ABC and MOM staining kits (Vector Laboratories). Antigen unmasking prior to immunostaining with the SP-C antibody was performed using citrate buffer together with a pressure cooker (Biocare Medical, Carlsbad, CA) according to the manufacturer's instructions. Antibodies were developed with DAB (Vector Laboratories) and counterstained with hematoxylin. Antibody dilutions were 1:2500 for $\beta$-tubulin, 1:200 for CC26, and 1:5000 for SP-C.

\section{Lung bud culture}

Lung rudiments dissected from E12.5 embryos were maintained for $72 \mathrm{~h}$ at $37^{\circ} \mathrm{C}$ on Transwell filters (Corning Costar, Cambridge, MA) in DMEM with 10\% fetal bovine serum, $2 \mathrm{mM}$ glutamine and 1\% antibiotic/antimycotic [18]. Branching morphogenesis was quantified by counting terminal peripheral end buds at $0,24,48$, and $72 \mathrm{~h}$ in culture.

\section{Morphometry}

Chord length measurements for saccules were performed as described [20]. Briefly, ten serial slides at least $50 \mu \mathrm{m}$ apart, which contained $5 \mu \mathrm{m}$ sections of paraffin-embed- 


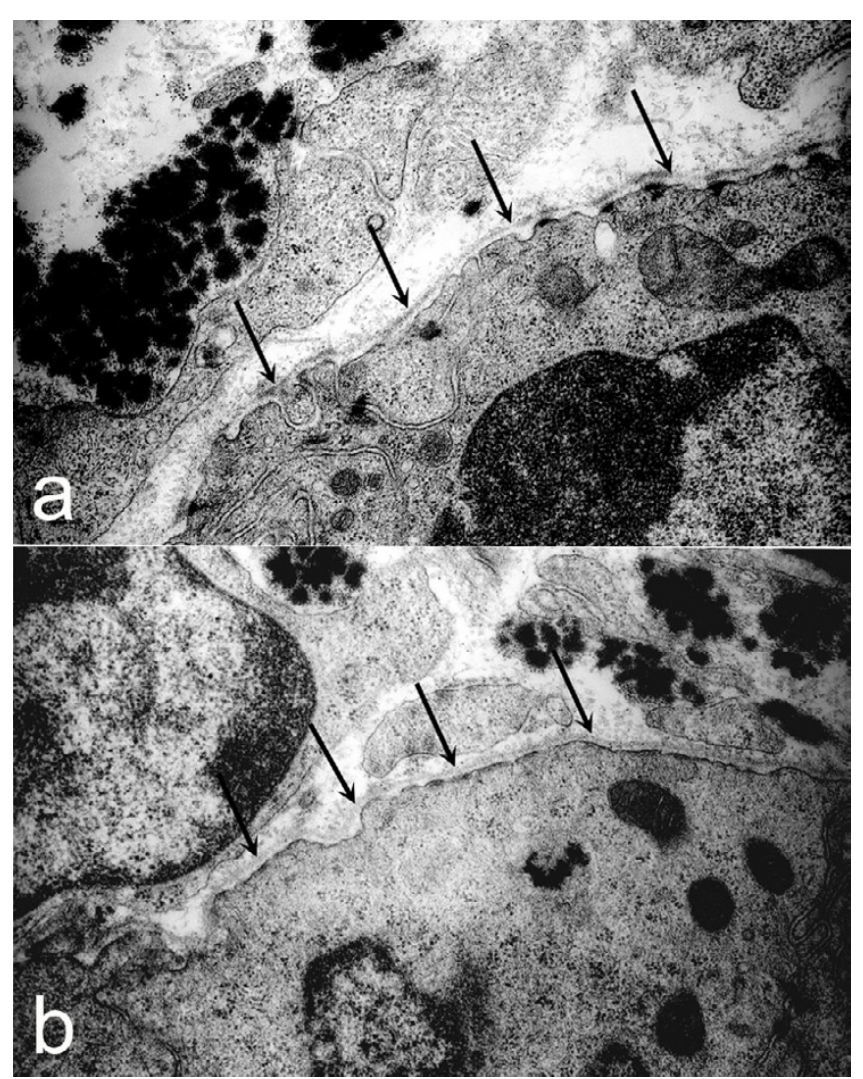

Figure 3

Airway basement membrane ultrastructure. Transmission electron micrographs of airways in both newborn littermate control (a) and Lamc2-/- (b) lungs revealed a continuous, electron dense basement membrane (arrows) underlying airway epithelial cells.

ded newborn Lamc2-/- and littermate control lungs (at least 3 of each) were stained with $\mathrm{H} \& \mathrm{E}$. Random images were acquired with the $40 \times$ objective on a Nikon Optiphot II microscope and a Zeiss Axiocam digital camera. Chord length was determined using the NIH image program. Fields containing large airways and vessels were excluded. Statistical analysis was determined by twotailed Student's t-Test.

\section{Results}

\section{Histology of Lamc2-/- lungs}

Lamc2-/- mice die within 3-5 days of birth presumably due to failure to thrive and involvement of the oral and gastroesophageal mucosa [15]. Lungs of Lamc2-/- (Fig. 1a) and littermate control (Fig. 1b) mice did not show significant differences in structural morphology at E14.5. Comparison of post-natal day 1-2 lungs from Lamc2-/- (Fig. 1c) and littermate control (Fig. 1d) showed an increase in saccular size. Measurement of chord length confirmed the increase in the Lamc2-/- $(25 \mu \mathrm{m})$ as compared to littermate control $(20 \mu \mathrm{m})$ saccule size, however this difference was not statistically significant ( $\mathrm{p}<0.07$, Student's t-Test).

\section{Basement membrane composition and ultrastructure}

Perturbation of laminin expression often leads to compensation by another laminin chain [21,22]. Previously, we found that deletion of laminin $\alpha 5$ expression by lung epithelial cells was associated with ectopic deposition of laminin $\alpha 4$ in airway basement membranes [11]. To determine if deficiency of laminin $\gamma 2$ is associated with changes in appearance of other laminin chains, we examined the lungs of Lamc2-/- mice by immunofluorescence for laminin $\alpha 1-5, \beta 1$, and $\gamma 1-2$ chains. Targeted deletion of laminin $\gamma 2$ was confirmed by lack of staining for laminin $\gamma 2$ in the Lamc2-/- lungs (Fig 2o). In the absence of laminin $\gamma 2$, expression of laminin $\alpha 3 \mathrm{~A}$ (Fig 2e) and $\alpha 3 \mathrm{~B}$ (Fig 2g) chains were markedly diminished but not absent and the expression of other laminin chains was similar to littermate controls (Fig 2). Since the laminin $\gamma 2$ chain is found only in laminin-332, this result is expected and parallels the finding in the skin of Lamc2-/- mice [15]. Immunofluorescence staining was also performed with antibody against entactin/nidogen but no differences were noted between Lamc2-/- and littermate controls (data not shown).

Ultrastructural analysis of conducting airway basement membrane in post-natal day 1 lung was accomplished by transmission electron microscopy. A continuous, welldefined, linear lamina densa of equivalent thickness was seen in both Lamc2-/- (Fig. 3b, arrows) and littermate control (Fig. 3a, arrows) airway basement membranes. Thus, although absence of laminin $\gamma 2$ leads to decrease in components of laminin-332 it does not affect basement membrane formation or change its morphology.

\section{Lung branching morphogenesis}

Because laminin $\gamma 2$ has increased expression in branching clefts during the pseudoglandular stage of lung development, it has been hypothesized that laminin $\gamma 2$ has a role in branching morphogenesis [14]. Accordingly, E12.5 littermate control (Fig. 4a-d) and Lamc2-/- (Fig. 4e-h) lung buds were removed and cultured for 3 days. The number of terminal peripheral end buds was quantified from photographs taken on day of explant and after 24,48 , and 72 $\mathrm{h}$ in culture (Fig. 4B). While the absolute number of terminal peripheral end buds was consistently less in Lamc2/- lungs compared with littermate controls, this difference was not significant and the rate of increase in terminal peripheral end buds was similar in Lamc2-/- and littermate controls. From this, we conclude that laminin $\gamma 2$, i.e. laminin-332, is not required for lung branching morphogenesis. 


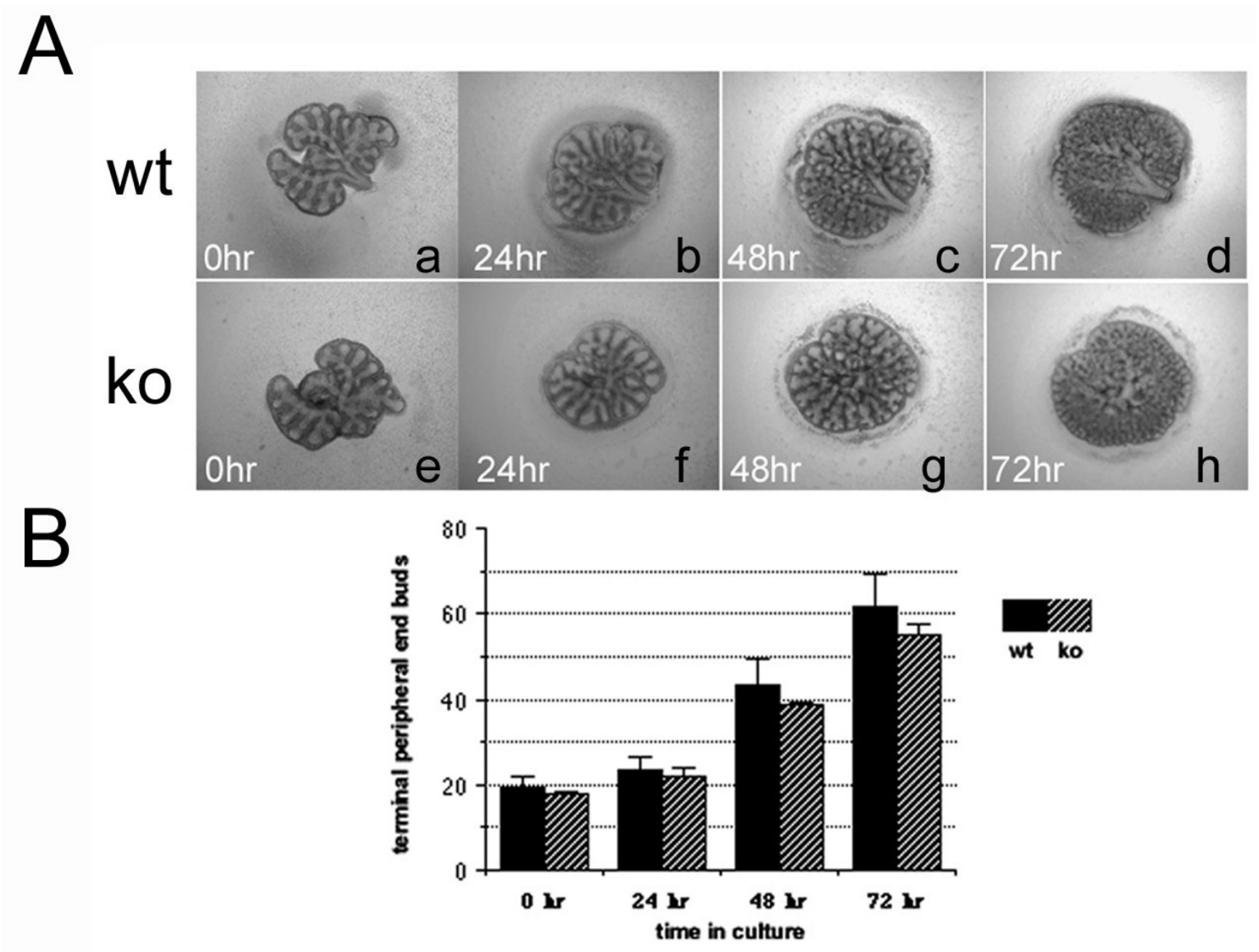

\section{Figure 4}

In vitro branching morphogenesis. Lung buds were removed from EI 2.5 littermate control and Lamc2-/- embryos and grown in culture for 72 hours. (A) Images of littermate control (a-d) and Lamc2-/- (e-h) lung buds were acquired at time of explant and after 24, 48, and 72 hours in culture. (B) Terminal peripheral airway buds were quantified and averaged (+/- SD) for each time point. No statistically significant differences were observed in littermate control and Lamc2-/- lungs. Analysis was performed with lung buds from 2 separate litters with at least 3 buds each for Lamc2-/- and littermate control. Original magnification 40x.

\section{Epithelial cell differentiation}

Absence of laminin $\alpha 5$ in the developing lung leads to abnormal differentiation of lung epithelial cells as shown by a marked decrease in alveolar type II cells and a near absence of alveolar type I cells [11]. As laminin $\gamma 2$ colocalizes with laminin $\alpha 5$ in sub-epithelial basement membranes of developing lungs, we investigated whether lack of laminin $\gamma 2$ would affect epithelial cell differentiation. Immunohistochemical staining against $\beta$-tubulin to detect ciliated cells (Fig. 5a-b), CC26 to detect Clara cells (Fig. 5c-d), PAS to detect mucous cells (data not shown), SP-C to detect alveolar type II cells (Fig. 5e-f), and aquaporin-5 to detect alveolar type I cells (Fig. 5g-h) all showed similar staining in Lamc2-/- (Fig. 5b, d, f, h) and littermate control (Fig. 5a, c, e, g) lungs. From these studies, we conclude that laminin $\gamma 2$ is not required for lung epithelial cell differentiation.

\section{Endothelial and smooth muscle cell development}

Although no differences in epithelial differentiation were noted, we examined development of other cell compartments. Endothelial cell and smooth muscle cell development were assessed with immunofluorescence staining for PECAM and $\alpha$-smooth muscle actin, respectively. As with the epithelial cell markers, no differences in staining patterns or intensity were detected using either the endothelial cell marker or the smooth muscle cell marker (data not shown). 


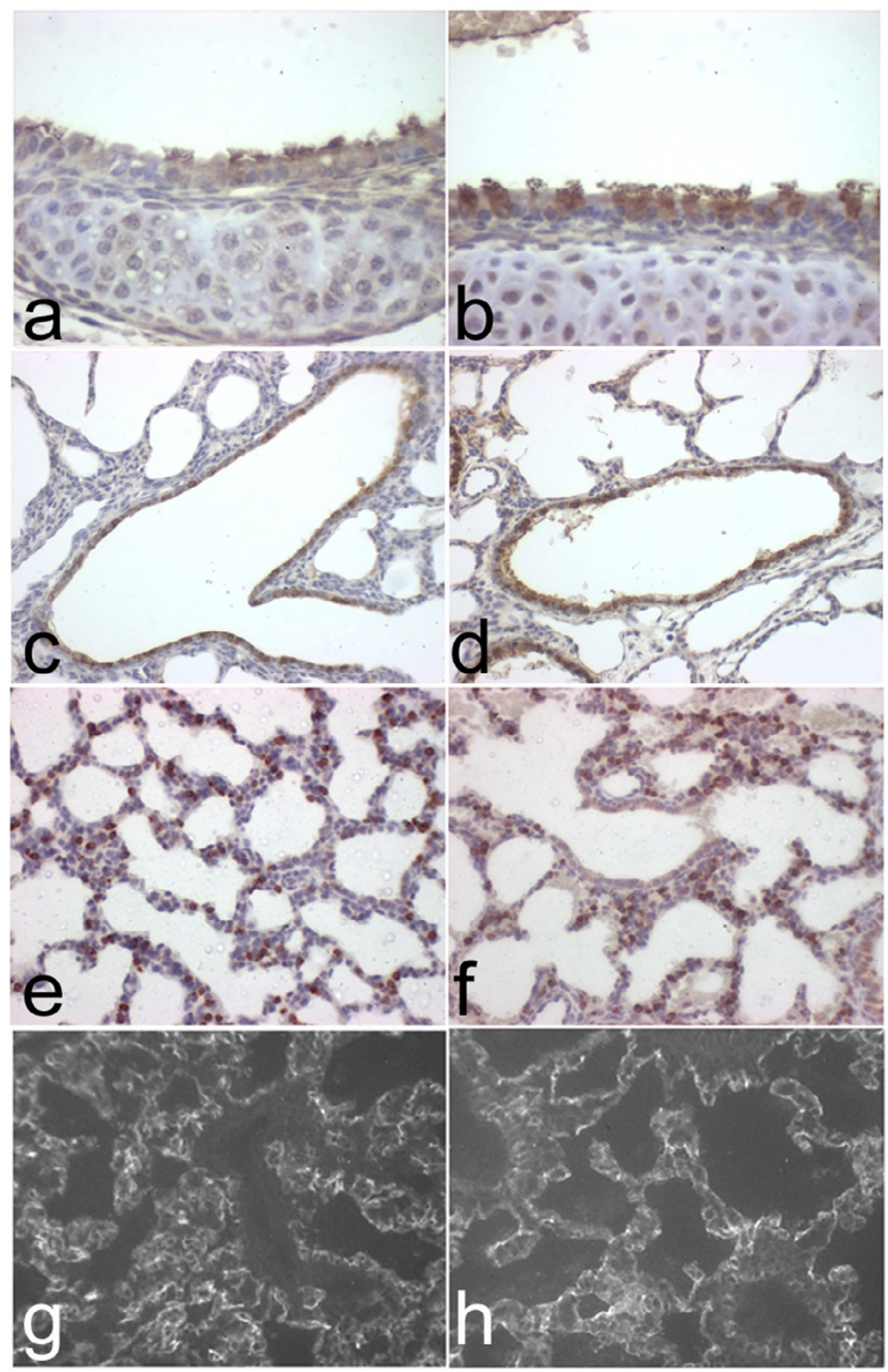

\section{Figure 5}

Epithelial cell differentiation. Sections of PI-2 littermate control (a, c, e, g) and Lamc2-/- (b, d, f, h) lungs were stained with antibodies to epithelial cell markers. Staining with the $\beta$-tubulin IV antibody for ciliated cells revealed similar staining in tracheas of littermate control (a) and Lamc2-/- (b) lungs. Staining with the CC26 antibody for Clara cells revealed similar findings in littermate control (c) and Lamc2-/- (d) lungs. Staining for the alveolar type II cell-specific marker pro-SP-C revealed no difference in proSP-C positive cells in littermate control (e) and Lamc2-/- (f) lungs. Immunofluorescence for the alveolar type I cell-specific marker aquaporin-5 revealed similar patterns in the Lamc2-/-lung (h) compared with littermate control (g). Original magnification 200x. 

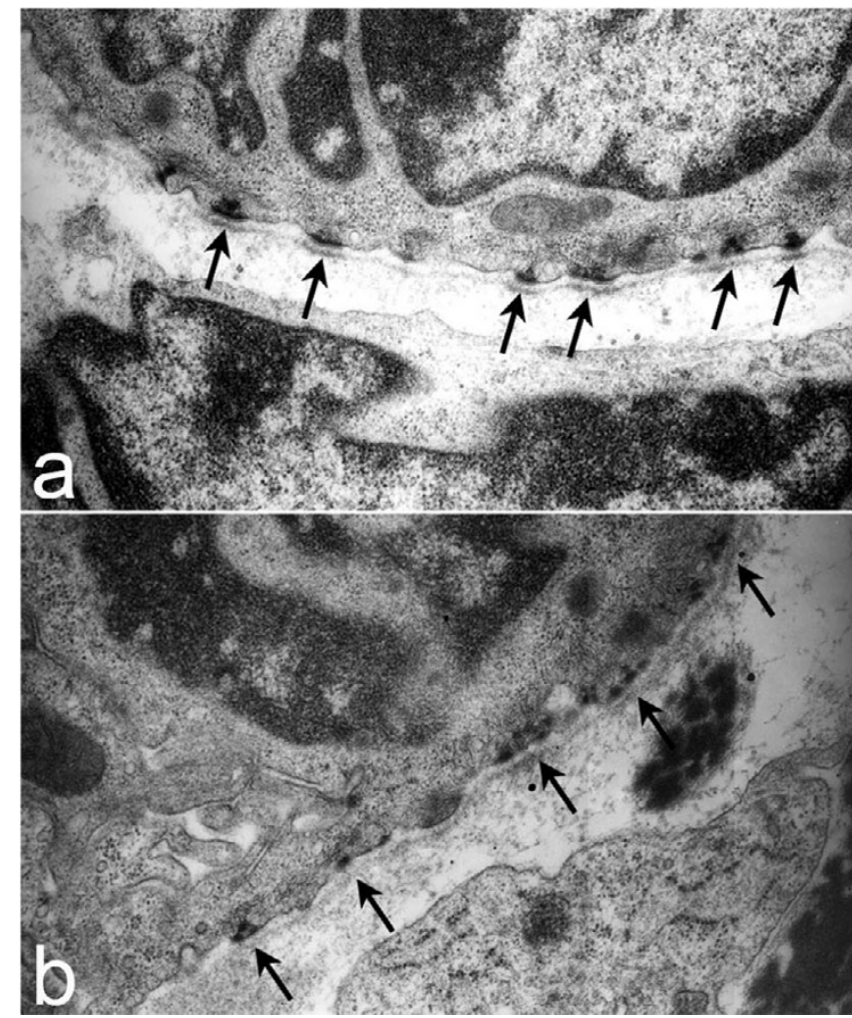

Figure 6

Ultrastructure of tracheal hemidesmosomes. Tracheas from PI-2 Lamc2-/- and littermate control mice were processed for transmission electron microscopy. Littermate control tracheas (a) had well-defined, organized hemidesmosomes with darkened areas in the lamina densa abutting the hemidesmosome (arrows). In contrast, hemidesmosomes in Lamc2-/tracheas (b) were less organized, the intracellular component was more diffuse, and the lamina densa directly below the hemidesmosomal areas lacked the electron density seen in the littermate control (arrows).

\section{Hemidesmosomes}

Laminin-332, the only laminin to contain laminin $\gamma 2$, is the only laminin associated with hemidesmosomes, a specialized transmembrane cell/matrix adhesion structure found at the basal aspect of basal cells of squamous and transitional epithelia. Hemidesmosomes are essential for basement membrane zone integrity with disruption leading to epidermolysis bullosa, a group of heritable blistering diseases [23]. In the lung, hemidesmosomes are restricted to tracheal and bronchial epithelial cells [24]. Since laminin-332 is required for hemidesmosome formation, we examined tracheal hemidesmosomes of Lamc2-/- mice. By transmission electron microscopy of post-natal day 1 tracheal epithelial cells, we found that hemidesmosomes of Lamc2-/- (Fig. 6b, arrows) mice are different than those of littermate controls (Fig. 6a, arrows). As seen in the cutaneous hemidesmosomes of

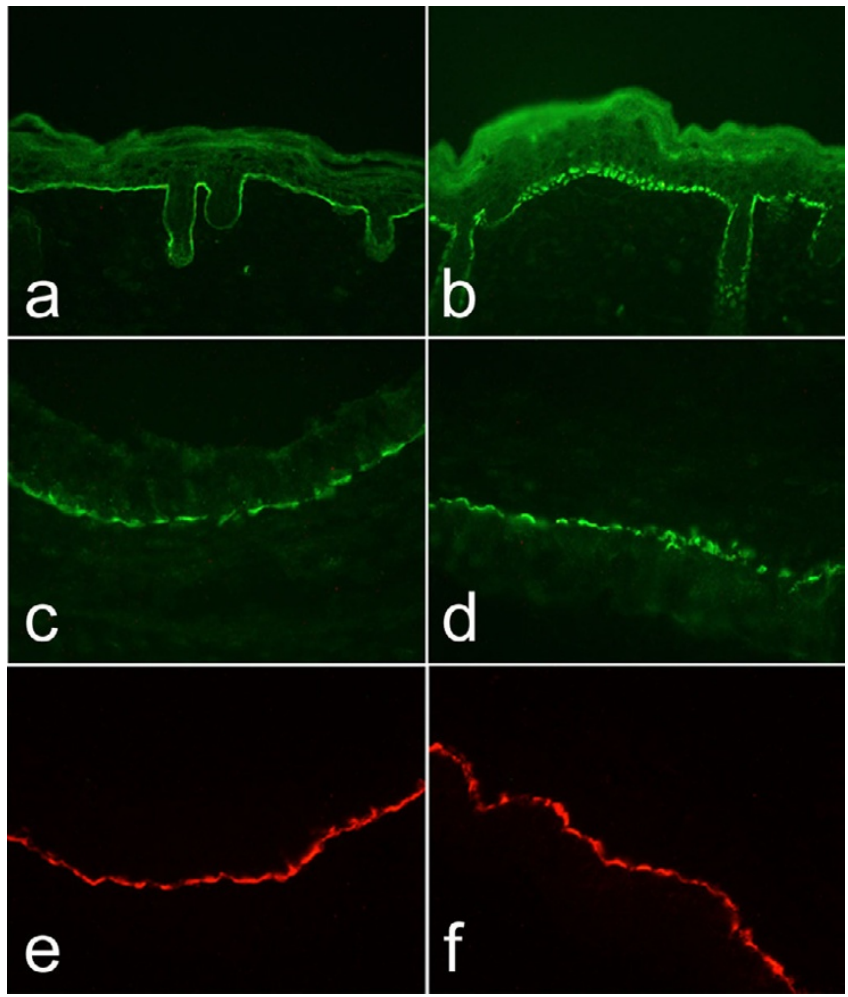

Figure 7

Hemidesmosomal proteins. Sections from PI-2 littermate control and Lamc2-/- skin and tracheas were stained with antibodies against BPI 80 and integrin $\beta 4$ to examine the distribution of hemidesmosomal proteins. In the skin $(a-b)$, staining with BPI 80 antibody showed a continuous pattern in the littermate control mouse, whereas a discontinuous pattern was seen with the Lamc2-/- (b) mouse. In the trachea (cd), BPI80 staining was similar in littermate control (c) and Lamc2-/- (d) mice. Immunofluorescence with antibody against integrin $\beta 4$ also did not reveal a difference in littermate control (e) and Lamc2-/- (f) tracheas. Original magnification 200x.

Lamc2-/- mice [15], tracheal hemidesmosomes are poorly formed with disorganization of the inner and outer plaques and decreased electron density of the lamina densa of the basement membrane underlying the hemidesmosome. Immunofluorescence staining for BP180 and integrin $\beta 4$, additional components of the hemidesmosome, in tracheal epithelium did not reveal a difference between littermate control (Fig. 7c, 7e, respectively) and Lamc2-/- (Fig 7d, 7f, respectively) lungs. This is in contrast to what was found in Lamc2-/- skin (Fig. 7b) where immunostaining for all hemidesmosomal proteins was diffuse and punctate while the littermate control skin (Fig. 7a) was continuous and localized [15].

\section{Laminin-322 receptors}

Manipulation of laminin ligands often results in perturbation of its receptors. Deletion of the laminin $\alpha 5$ chain 


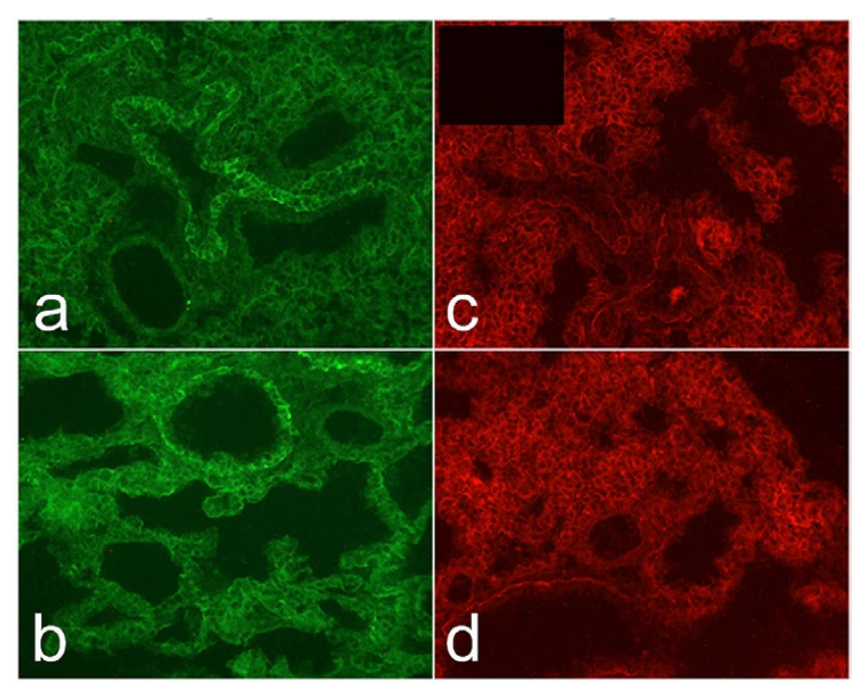

Figure 8

Expression of laminin-332 receptors. Sections from PI-2 littermate control and Lamc2-/-lungs were stained with antibodies against integrins $\alpha 3$ and $\alpha 6$. No differences in intensity or localization were detected by immunofluorescence for integrins $\alpha 3$ (a-b) or $\alpha 6$ (c-d) between littermate control (a, c) and Lamc2-/- (b, d) lungs. No immunofluorescence was detected when primary antibody was omitted from the procedure (inset panel c). Original magnification 200x.

leads to abnormal localization of its cellular receptors Lutheran and integrin $\alpha 3[11,25]$. Accordingly, we examined the localization of two common laminin-332 receptors, integrin $\alpha 3$ and integrin $\alpha 6$. Integrin $\alpha 3$ is important for cell-adhesion and integrin $\alpha 6$ pairs with integrin $\beta 4$ in the hemidesmosome. Immunofluorescence with antibodies against integrins $\alpha 3$ (Fig 8a-b) and $\alpha 6$ (Fig $8 c-d$ ) showed similar staining in littermate control (Fig 8a, c) and Lamc2-/- (Fig. 8b, d) lungs.

\section{Discussion}

Laminin-332, the only laminin containing the laminin $\beta 3$ and $\gamma 2$ chains, was first detected in human basement membranes and underneath hemidesmosomes decades ago [26]. The primary structures of the individual chains of laminin-332 were determined in the early 1990s and laminin-332 and its components have been studied extensively in subsequent years. Laminin-332 containing the laminin $\gamma 2$ chain is produced by epithelial cells and is widely distributed in basement membranes of most epithelia, including skin, lung, gastrointestinal tract, kidney, prostate, ovary, and blood vessels of spleen and thymus $[12,27,28]$. Knockout and transgenic mice technologies have enabled exploration of specific functions of individual laminin-332 components in mouse development. Targeted deletion of the laminin $\alpha 3$ chain leads to perinatal death with a severe blistering disease similar to human junctional epidermolysis bullosa, and defective late stage differentiation of ameloblasts in developing incisors [29]. A null mutation in the Lamb3 gene from spontaneous insertion of an intracisternal-A particle at an exon/intron junction also results in blisters and death hours after birth [30]. Lamc2-/- mice suffer perinatal death and exhibit skin lesions that recapitulate human junctional epidermolysis bullosa with induced apoptosis in the basal cells of the abnormal skin [15]. Although laminin-332 is seen in many organs, most of the focus has been on skin during the characterization of mice with mutations in any of the laminin-332 constituents. In this report, we focus on lung development in Lamc2-/- mice.

Lamc2, present in laminin-332, is found in the epithelial airway and alveolar basement membranes of adult lungs and epithelial basement membranes of lung from the pseudoglandular to the alveolar stage of lung development [14]. In human lung during the pseudoglandular stage, immunodetection of laminin $\gamma 2$ and laminin-332 revealed higher intensity of fluorescence in the clefts of the ramifications of the growing respiratory tubules leading the authors to hypothesize a role in branching morphogenesis [14]. Because laminin-332 co-localizes with laminin-111, which is a known effector of lung branching morphogenesis in vitro, speculation of a role for laminin332 in branching morphogenesis was plausible. In our study, we were able to directly examine branching morphogenesis in the absence of laminin $\gamma 2$ and laminin-332 through use of the Lamc2-/- mouse. We found that deficiency of laminin $\gamma 2$ did not affect lung branching morphogenesis of in vitro lung bud cultures. This result is reminiscent of our finding normal lung branching morphogenesis in the Lama5-/- mouse, even though laminin $\alpha 5$ co-localized with laminin $\alpha 1$ [18]. Of note, the null mutation of integrin $\alpha 3$, a major ligand for both laminin $\alpha 3$ and laminin $\alpha 5$ containing laminins, led to abnormal branching morphogenesis [31] thus normal branching morphogenesis in laminin 332 deficient and laminin $\alpha 5$ null mice is rather unexpected. In the case of the Lamc2-/mouse, only laminin-332 is absent so that other laminin $\alpha 3$ chain containing laminins (laminins-311 or -321) are still present and can contribute to the process of branching morphogenesis. An alternate, and perhaps more attractive, conclusion is that within the epithelial-derived laminin chains (those with laminin $\alpha 1, \alpha 3$, and $\alpha 5$ chains), no redundancy of function exists for laminin chains and only laminins containing the laminin $\alpha 1$ chain exert effects on lung branching morphogenesis. To resolve this, one needs to examine lung branching morphogenesis in a Lama1-/- mouse or a double Lama3/ Lama5 knockout mouse.

Again, based on localization of laminin-332 and $\gamma 2$ during development, roles in lung epithelial differentiation 
and alveolization were also suggested $[12,14]$. This idea fits with studies showing that laminin-332 stabilizes the phenotype of primary alveolar epithelial cells in culture [32-34]. However, we found normal expression and localization of markers of airway and alveolar epithelial cells in Lamc2-/- lungs. This finding contrasts with the lungs of mice lacking laminin $\alpha 5$ in which there is a marked impairment in differentiation of distal epithelial cells [11]. With respect to lung alveolization, we did note a mild increase in saccule size in the Lamc2-/- compared with littermate controls. Whether laminin $\gamma 2$ or laminin332 is important for later stages of lung development, specifically alveolization remains to be determined since Lamc2-/- mice died before alveolization occurs. That lack of laminin $\gamma 2$ did not significantly affect lung epithelial cell differentiation while perturbation of laminin $\alpha 5$ had a dramatic effect again indicates that laminins have specific, non-overlapping functions during lung development.

In the absence of a laminin chain, compensation by ectopic expression of another laminin of the same chain group can occur. Lamb1 compensates for lack of Lamb2 in the kidney, upregulation of Lama4 is seen with loss of Lama2 in muscle, deletion of Lama5 leads to ectopic Lama2 and Lama4 in ectoderm and intestines $[21,22,35,36]$. However, a compensatory response was not detected with deletion of laminin $\gamma 2$ in the lung or in the skin. The reason for this is unknown but it may relate to the uniqueness of laminin-332 in that it is the only laminin known to contain the $\beta 3$ and $\gamma 2$ chains and it is the only laminin present in hemidesmosomes.

By transmission electron microscopy, tracheal hemidesmosomes in Lamc2-/- mice were different from those of the littermate control. This finding is consistent with cutaneous hemidesmosomes in the Lamc2-/- and the Lama3-/- mice. However, even though the hemidesmosomes appeared abnormal at the ultrastructural level, immunofluorescence staining for other components of hemidesmosomes was similar between Lamc2-/- and littermate control lungs. In contrast, immunostaining for cutaneous basement membrane zone proteins in Lamc2-/ - and Lama3-/- both showed abnormal distribution of these proteins compared with controls $[15,29]$. In addition, skin epithelial and oral and bladder mucosa of Lamc2-/- and Lama3-/- had areas of blister formation while no areas of blistered epithelium were found in Lamc2-/- tracheas. This suggests that abnormal hemidesmosomes in Lamc2-/- tracheas did not produce a functional defect or that the tracheas are not mechanically stressed enough to blister. Alternatively, tracheal hemidesmosomes may have different function compared to hemidesmosomes in other tissues. In people with epidermolysis bullosa, the main pathologic feature is skin blistering with abnormal hemidesmosomes. Rare cases of laryngotracheal involvement have been reported but airway obstruction has not been implicated as a significant cause of mortality in these patients [37-39]. Thus, our finding of normal appearance, integrity, and presumably function, of tracheal epithelium despite abnormal hemidesmosomes in the Lamc2-/- mice is consistent with infrequent abnormalities in humans.

While we did not observe a significant role for laminin $\gamma 2$ and laminin-332 in lung development, physiologic roles of this laminin must exist. Laminin-332 may facilitate alveolar epithelial repair via effects on cell migration. By in situ hybridization, immunohistochemistry, and immunoelectron microscopy, regenerating epithelial cells in cryptogenic organizing pneumonia and in idiopathic pulmonary fibrosis both express laminin $\gamma 2$ in response to injury [40]. In addition, a recent report shows that laminin $\gamma 2$ is not only present in the basement membrane but also in the cytoplasm of injured epithelial cells and in columnar epithelium of allergic asthmatics [41]. Moreover, this laminin may influence tumor cell behavior [42]. Tumor cell lines often express laminin-332 and the expression is enhanced by epidermal growth factor [43]. In lung tumors, expression of the laminin $\gamma 2$ chain was strong in squamous cell carcinomas, adenocarcinomas, and large cell carcinomas, with immunoreactive cells localizing to the epithelial-stromal interface of tumor clusters [44]. Inactivation of laminin-322 genes by aberrant methylation in prostate cancer and bladder cancer samples correlated with poor prognosis [45-47]. Laminin $\gamma 2$ can be found in the cytoplasm of carcinoma cells invading into interstitial stroma while laminin $\alpha 3$ and $\beta 3$ chains are only found in the basement membrane [48].

\section{Conclusion}

In summary, analysis of Lamc2-/- lungs reveals that laminin $\gamma 2$ and its associated laminin-332 are not essential for virtually normal lung development to the saccular stage. Peri-natal death of Lamc2-/- mice prior to completion of alveolization precludes a definitive conclusion about the requirement of Lamc 2 for alveolization. However, the prominence of laminin $\gamma 2$ in alveolar walls during lung development and the adult lung points to important physiologic functions.

\section{Competing interests}

The author(s) declare that they have no competing interests.

\section{Authors' contributions}

NN participated in the design of the study, carried out the lung bud cultures, immunofluorescence staining, statistical analysis, supervised the optimization of immunostaining, evaluated the data, and drafted the manuscript. JS 
carried out the immunohistochemical staining, morphometry, evaluated the data, and helped to draft the manuscript. LP and JU produced the Lamc2-/- mouse and helped to draft the manuscript. GM made the laminin $\gamma 2$ antibody and helped to draft the manuscript. RS conceived the study, participated in its design and coordination, evaluated the data, and helped to draft the manuscript. All authors read and approved the final manuscript.

\section{Acknowledgements}

We thank Dale Abrahamson, Takako Sasaki, Zhi Liu, and C. Michael DiPersio for antibodies. We thank Michelle Meyer for assistance with genotyping. We thank Xianmin Meng and John Klement for assistance in generation of the Lamc2-/- mouse. We thank Jeff Miner for review of this manuscript. This work was supported by $\mathrm{HL75039}$ (NMN) and HL29594 (RMS) from NIH/ NHLBI, by the Alan A. and Edith L. Wolff Charitable Trust (RMS), by POI AR38923 (JU) and R03 AR47III (LP) from NIH/NIAMS and Dystrophic Epidermolysis Bullosa Association (LP), and by Debra UK the Epidermolyse Bulleuse d"Entraide and GAT 020I from the Assoication Francaise contre les Myopathies and Telethon Italia Onlus (GM).

\section{References}

I. Miner JH, Yurchenco PD: Laminin functions in tissue morphogenesis. Annu Rev Cell Dev Biol 2004, 20:255-284.

2. Aumailley M, Bruckner-Tuderman L, Carter WG, Deutzmann R, Edgar D, Ekblom P, Engel J, Engvall E, Hohenester E, Jones JC, Kleinman HK, Marinkovich MP, Martin GR, Mayer U, Meneguzzi G, Miner JH, Miyazaki K, Patarroyo M, Paulsson M, Quaranta V, Sanes JR, Sasaki T, Sekiguchi K, Sorokin LM, Talts JF, Tryggvason K, Uitto J, Virtanen I, von der Mark K, Wewer UM, Yamada Y, Yurchenco PD: A simplified laminin nomenclature. Matrix Biol 2005, 24(5):326-332.

3. Gersdorff N, Kohfeldt E, Sasaki T, Timpl R, Miosge N: Laminin gamma3 chain binds to nidogen and is located in murine basement membranes. I Biol Chem 2005, 280(23):22 I 46-22 I 53.

4. Miner JH, Patton BL, Lentz SI, Gilbert DJ, Snider WD, Jenkins NA, Copeland NG, Sanes JR: The laminin alpha chains: expression, developmental transitions, and chromosomal locations of alpha $\mathrm{I}-5$, identification of heterotrimeric laminins $8-\mathrm{II}$, and cloning of a novel alpha3 isoform. J Cell Biol 1997, 137(3):685-70I.

5. Virtanen I, Laitinen A, Tani T, Paakko P, Laitinen LA, Burgeson RE, Lehto VP: Differential expression of laminins and their integrin receptors in developing and adult human lung. $\mathrm{Am} J$ Respir Cell Mol Biol 1996, I 5(2): I 84-196.

6. Pierce RA, Griffin GL, Mudd MS, Moxley MA, Longmore WJ, Sanes JR, Miner JH, Senior RM: Expression of laminin alpha3, alpha4, and alpha5 chains by alveolar epithelial cells and fibroblasts. Am J Respir Cell Mol Biol 1998, I 9(2):237-244.

7. Virtanen I, Gullberg D, Rissanen J, Kivilaakso E, Kiviluoto T, Laitinen LA, Lehto VP, Ekblom P: Laminin alphal-chain shows a restricted distribution in epithelial basement membranes of fetal and adult human tissues. Exp Cell Res 2000, 257(2):298-309.

8. Schuger L, O'Shea S, Rheinheimer J, Varani J: Laminin in lung development: effects of anti-laminin antibody in murine lung morphogenesis. Dev Biol 1990, 137(1):26-32.

9. Willem M, Miosge N, Halfter W, Smyth N, Jannetti I, Burghart E, Timpl R, Mayer U: Specific ablation of the nidogen-binding site in the laminin gamma I chain interferes with kidney and lung development. Development 2002, I 29( I I):27I I-2722.

10. Relan NK, Yang Y, Beqaj S, Miner JH, Schuger L: Cell elongation induces laminin alpha2 chain expression in mouse embryonic mesenchymal cells: role in visceral myogenesis. J Cell Biol 1999, I 47(6): | 34|-|350.

II. Nguyen NM, Kelley DG, Schlueter JA, Meyer MJ, Senior RM, Miner $\mathrm{JH}$ : Epithelial laminin alpha5 is necessary for distal epithelial cell maturation, VEGF production, and alveolization in the developing murine lung. Dev Biol 2005, 282(I): I II-I 25.
12. Mizushima H, Koshikawa N, Moriyama K, Takamura H, Nagashima $Y$, Hirahara F, Miyazaki K: Wide distribution of laminin-5 gamma 2 chain in basement membranes of various human tissues. Horm Res 1998, 50(Suppl 2):7-I4.

13. Miosge N, Kluge JG, Studzinski A, Zelent C, Bode C, Sprysch P, Burgeson RE, Herken R: In situ-RT-PCR and immunohistochemistry for the localisation of the mRNA of the alpha 3 chain of laminin and laminin-5 during human organogenesis. Anat Embryol (Berl) 2002, 205(5-6):355-63. Epub 2002 Jun 28.

14. Coraux C, Meneguzzi G, Rousselle P, Puchelle E, Gaillard D: Distribution of laminin 5 , integrin receptors, and branching morphogenesis during human fetal lung development. Dev Dyn 2002, 225(2): 176-185.

15. Meng X, Klement JF, Leperi DA, Birk DE, Sasaki T, Timpl R, Uitto J, Pulkkinen L: Targeted inactivation of murine laminin gamma2-chain gene recapitulates human junctional epidermolysis bullosa. J Invest Dermatol 2003, I 2 I (4):720-73I.

16. Garbe JH, Gohring W, Mann K, Timpl R, Sasaki T: Complete sequence, recombinant analysis and binding to laminins and sulphated ligands of the $\mathbf{N}$-terminal domains of laminin alpha3B and alpha5 chains. Biochem J 2002, 362(Pt I):2I3-22I.

17. Senior RM, Griffin GL, Mudd MS, Moxley MA, Longmore WJ, Pierce RA: Entactin expression by rat lung and rat alveolar epithelial cells. Am J Respir Cell Mol Biol 1996, I4(3):239-247.

18. Nguyen NM, Miner JH, Pierce RA, Senior RM: Laminin alpha 5 is required for lobar septation and visceral pleural basement membrane formation in the developing mouse lung. Dev Biol 2002, 246(2):23I-244.

19. Yuen HW, Ziober AF, Gopal P, Nasrallah I, Falls EM, Meneguzzi G, Ang HQ, Ziober BL: Suppression of laminin-5 expression leads to increased motility, tumorigenicity, and invasion. Exp Cell Res 2005, 309(I): 198-210.

20. Atkinson JJ, Holmbeck K, Yamada S, Birkedal-Hansen H, Parks WC, Senior RM: Membrane-type I matrix metalloproteinase is required for normal alveolar development. Dev Dyn 2005, 232(4): $1079-1090$.

21. Noakes PG, Miner JH, Gautam M, Cunningham JM, Sanes JR, Merlie JP: The renal glomerulus of mice lacking s-laminin/laminin beta 2: nephrosis despite molecular compensation by laminin beta I. Nat Genet 1995, 10(4):400-406.

22. Patton BL, Miner JH, Chiu AY, Sanes JR: Distribution and function of laminins in the neuromuscular system of developing, adult, and mutant mice. J Cell Biol I997, I39(6): I507-I52I.

23. Uitto J, Richard G: Progress in epidermolysis bullosa: genetic classification and clinical implications. Am J Med Genet C Semin Med Genet 2004, I 3 I C(I):6I-74.

24. Michelson PH, Tigue M, Jones JC: Human bronchial epithelial cells secrete laminin 5 , express hemidesmosomal proteins, and assemble hemidesmosomes. J Histochem Cytochem 2000, 48(4):535-544.

25. Kikkawa $\mathrm{Y}$, Virtanen I, Miner JH: Mesangial cells organize the glomerular capillaries by adhering to the $G$ domain of laminin alpha5 in the glomerular basement membrane. J Cell Biol 2003, 16I(1):187-96. Epub 2003 Apr 7..

26. Verrando P, Hsi BL, Yeh CJ, Pisani A, Serieys N, Ortonne JP: Monoclonal antibody GB3, a new probe for the study of human basement membranes and hemidesmosomes. Exp Cell Res 1987, 170(1): 116-128.

27. Carter WG, Ryan MC, Gahr PJ: Epiligrin, a new cell adhesion ligand for integrin alpha 3 beta $I$ in epithelial basement membranes. Cell 1991, 65(4):599-610.

28. Aberdam D, Aguzzi A, Baudoin C, Galliano MF, Ortonne JP, Meneguzzi G: Developmental expression of nicein adhesion protein (laminin-5) subunits suggests multiple morphogenic roles. Cell Adhes Commun 1994, 2(2): I I5-129.

29. Ryan MC, Lee K, Miyashita Y, Carter WG: Targeted disruption of the LAMA3 gene in mice reveals abnormalities in survival and late stage differentiation of epithelial cells. J Cell Biol 1999, 145(6): I $309-1323$.

30. Kuster JE, Guarnieri MH, Ault JG, Flaherty L, Swiatek PJ: IAP insertion in the murine LamB3 gene results in junctional epidermolysis bullosa. Mamm Genome 1997, 8(9):673-68I.

31. Kreidberg JA, Donovan MJ, Goldstein SL, Rennke H, Shepherd K, Jones RC, Jaenisch R: Alpha 3 beta I integrin has a crucial role in kidney and lung organogenesis. Development 1996, I 22(II):3537-3547. 
32. Olsen CO, Isakson BE, Seedorf GJ, Lubman RL, Boitano S: ExtracelIular matrix-driven alveolar epithelial cell differentiation in vitro. Exp Lung Res 2005, 3 I (5):46 I-482.

33. Isakson BE, Lubman RL, Seedorf GJ, Boitano S: Modulation of pulmonary alveolar type II cell phenotype and communication by extracellular matrix and KGF. Am J Physiol Cell Physiol 200I, 28 I (4): CI $29 \mid-9$.

34. Isakson BE, Seedorf GJ, Lubman RL, Boitano S: Heterocellular cultures of pulmonary alveolar epithelial cells grown on laminin-5 supplemented matrix. In Vitro Cell Dev Biol Anim 2002, 38(8):443-449.

35. Miner JH, Cunningham J, Sanes JR: Roles for laminin in embryogenesis: exencephaly, syndactyly, and placentopathy in mice lacking the laminin alpha5 chain. J Cell Biol 1998, | 43(6): I7|3-|723.

36. Bolcato-Bellemin AL, Lefebvre O, Arnold C, Sorokin L, Miner JH, Kedinger M, Simon-Assmann P: Laminin alpha5 chain is required for intestinal smooth muscle development. Dev Biol 2003, 260(2):376-390.

37. Smith LT, Miller AW, Kirz DA, Elias S, Brumbaugh S, Holbrook KA: Separation of noncutaneous epithelia in a fetus diagnosed in utero with junctional epidermolysis bullosa. Pediatr Res 1992, 3 I(6):56I-566.

38. Thompson JW, Ahmed AR, Dudley JP: Epidermolysis bullosa dystrophica of the larynx and trachea. Acute airway obstruction. Ann Otol Rhinol Laryngol 1980, 89(5 Pt I):428-429.

39. Liu RM, Papsin BC, de Jong AL: Epidermolysis bullosa of the head and neck: a case report of laryngotracheal involvement and I 0 -year review of cases at the Hospital for Sick Children. J Otolaryngol 1999, 28(2):76-82.

40. Lappi-Blanco E, Kaarteenaho-Wiik R, Salo S, Sormunen R, Maatta M, Autio-Harmainen $H$, Soini $Y$, Paakko P: Laminin-5 gamma2 chain in cryptogenic organizing pneumonia and idiopathic pulmonary fibrosis. Am J Respir Crit Care Med 2004, I 69(I):27-33. Epub 2003 Sep 18..

4I. Amin K, Janson C, Seveus L, Miyazaki K, Virtanen I, Venge P: Uncoordinated production of Laminin-5 chains in airways epithelium of allergic asthmatics. Respir Res 2005, 6: I I0.

42. Katayama M, Sekiguchi K: Laminin-5 in epithelial tumour invasion. J Mol Histol 2004, 35(3):277-286.

43. Mizushima H, Miyagi Y, Kikkawa Y, Yamanaka N, Yasumitsu H, Misugi K, Miyazaki K: Differential expression of laminin-5/ladsin subunits in human tissues and cancer cell lines and their induction by tumor promoter and growth factors. J Biochem (Tokyo) 1996, I 20(6): I | 96-1202.

44. Maatta M, Soini Y, Paakko P, Salo S, Tryggvason K, Autio-Harmainen $\mathrm{H}$ : Expression of the laminin gamma2 chain in different histological types of lung carcinoma. A study by immunohistochemistry and in situ hybridization. J Pathol 1999, | 88(4):36|-368.

45. Sathyanarayana UG, Toyooka S, Padar A, Takahashi T, Brambilla E Minna JD, Gazdar AF: Epigenetic inactivation of laminin-5encoding genes in lung cancers. Clin Cancer Res 2003, 9(7):2665-2672.

46. Sathyanarayana UG, Padar A, Suzuki M, Maruyama R, Shigematsu H, Hsieh JT, Frenkel EP, Gazdar AF: Aberrant promoter methylation of laminin-5-encoding genes in prostate cancers and its relationship to clinicopathological features. Clin Cancer Res 2003, 9(I 7):6395-6400.

47. Sathyanarayana UG, Maruyama R, Padar A, Suzuki M, Bondaruk J, Sagalowsky A, Minna JD, Frenkel EP, Grossman HB, Czerniak B, Gazdar AF: Molecular detection of noninvasive and invasive bladder tumor tissues and exfoliated cells by aberrant promoter methylation of laminin-5 encoding genes. Cancer Res 2004, 64(4): I 425- I430.

48. Kagesato $Y$, Mizushima H, Koshikawa N, Kitamura H, Hayashi H, Ogawa N, Tsukuda M, Miyazaki K: Sole expression of laminin gamma 2 chain in invading tumor cells and its association with stromal fibrosis in lung adenocarcinomas. Jpn J Cancer Res 200।, 92(2): I84-192.

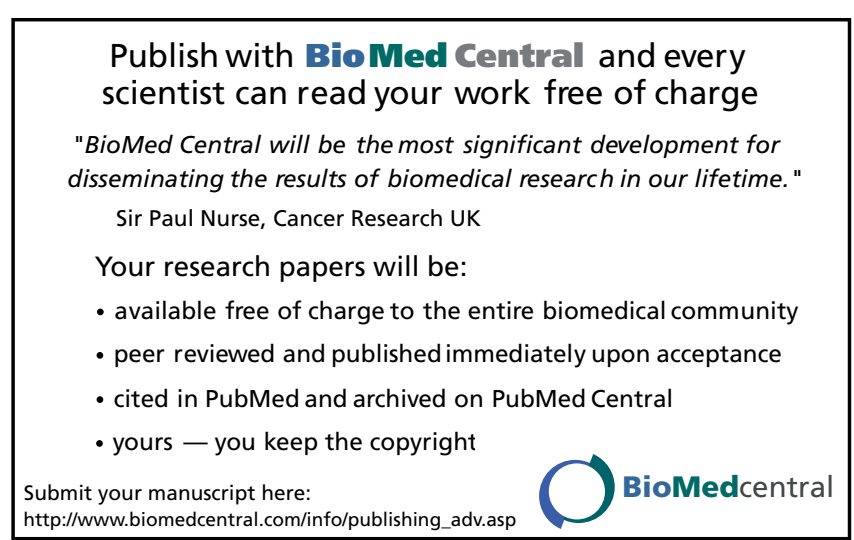

